\title{
Büyük boyutlara ulaşmış odontojenik kistlerin tedavisinde konservatif yaklaşım: İki olgu sunumu
}

\author{
Mehmet Melih Ömezli(0000-0002-6606-6593) ${ }^{\alpha}$, Ferhat Ayrancı(0000-0001-7126-569) ${ }^{\alpha}$, Hale Yurtyapan(0000-0001-7126-569) ${ }^{\alpha}$, \\ Kadircan Kahveci(0000-0001-8532-3367) ${ }^{\alpha}$ \\ Selcuk Dent J, 2021; 8: 561-565 (Doi: 10.15311/selcukdentj.550819) \\ Bașvuru Tarihi: 13 Subat 2020 \\ Yayına Kabul Tarihi: 05 Haziran 2020
}

\begin{abstract}
ÖZ
Büyük boyutlara ulaşmış odontojenik kistlerin tedavisinde konservatif yaklaşım: İki olgu sunumu

Odonotojenik Keratokist çenelerde görülen en agresif kistlerdendir. Dental lamina artıklarından gelişir, nüks ve dokulara infiltrasyon özelliği vardır. Dentigeröz kist ikinci en çok görülen odontojenik kisttir ve çoğu zaman semptom vermez. Bu olgu sunumunda geniş yerleşimli bu iki kistin marsupyalizasyon vakası sunulmaktadır. Her iki olguda, klinik ve radyolojik muayene sonrası mandibula yerleşimli, ağrısız, intraoral ve ekstraoral ekspansiyon yapmamış geniş radyolüsent lezyon tespit edildi. Lokal anestezi altında ilgili bölgelerden tam kalınlık flep kaldırılarak kemikte kavite açıldı. Kistik sıvı boşaltılarak kavite yıkandı ve kavite açıklığı korunacak şekilde gaz iyodoform suture edildi. Odontojenik keratokist ve dentigeröz kist çoğunlukla mandibula posterior bölgede görülen ve büyük boyutlara ulaşabilen lezyonlardır. Tedavide lezyonun büyüklüğüne göre enükleasyon ve marsupyalizasyon yapılabilir. Operasyon sonrası histopatolojik inceleme yapılmalı ve hastalar uzun dönem takibi edilmelidir.
\end{abstract}

\section{ANAHTAR KELIMELER}

Keratokist, Dentigeröz kist, Marsupyalizasyon

Marsupyalizasyon, ilk olarak Partsch tarafından literatüre kazandırımış, ${ }^{1}$ kiste komşu kemik duvarında bir pencere açılıp kist içeriğinin debridmanı ve epitelin çevre yumuşak dokuya suture edilerek kist kavitesiyle oral kavitenin arasında bağlantı kurulmasını ifade eden bir tedavi yaklaşımıdır. ${ }^{2,3}$ Marsupyalizasyon etkin bir konservatif yöntemdir ve odontojenik kistik lezyonlar ile kistik benign kemik tümörlerin tedavisinde yaygın olarak uygulananmaktadır. ${ }^{4}$ Marsupyalizasyon tedavisi; intramural basıncın azaltılması ile kist kavitesinde yeni kemik oluşumuna olanak sağlar ve inferior alveolar sinir, maksiller sinüs gibi anatomik yapıları koruyarak mandibula fraktürü gibi komplikayonların ortaya çıkma riskini minimalize eder. ${ }^{5}$ Aynı zamanda marsupyalizasyon nüks insidansını azaltarak lezyon ile ilişkili gömülü dişlerin sürdürülmesine de olanak sağlayabilmektedir. ${ }^{4,6} \mathrm{Bu}$ yöntemin, özellikle agresif seyirli büyük boyutlara ulaşmış kistlerde, enükleasyon veya rezeksiyon gibi invaziv tedavi seçeneklerine alternatif olarak önemli bir rolü bulunmaktadır. ${ }^{3}$

Odonotojenik Keratokist (OK) dental lamina

\begin{abstract}
Conservative Approach of the Treatment of Large Odontogenic Cysts: Report of Two Cases

Odontogenic keratocyst is the most aggressive cyst that develops from dental lamina remnants. It recurrence and infiltrate to tissues. Dentigerous cyst is the second most common cyst and often does not cause symptoms. In this case report, marsupialization of these two cysts with large settlement is presented. In both cases, after clinical and radiological examination, a large radiolucent lesion was determined at the mandibula, without pain, intraoral and extraoral expansions. Under local anesthesia, full thickness flap was raised and the cavity was opened in the bone. The cyst fluid was evacuated. Then, the gas iodoform sutured to maintain cavity gap. Odontogenic keratocyst and dentigerous cyst are mostly lesions have seen in the posterior region of the mandible and reaching large sizes. Enucleation and marsupialisation can be performed according to the size of the lesion in treatment. Patients should be followed for a long time with postoperative histopathological examination.
\end{abstract}

\section{KEYWORDS}

Keratocyst, Dentigerous cyst, Marsupialization

artıklarından gelişen, lokal agresif davranışı ve dokulara infiltrasyon özelliği nedeniyle yüksek nüks potansiyeline sahip gelişimsel bir odontojenik kisttir.7, 8 Odontojenik kistlerinin yaklaşık \% 10'unu oluşturan OK'ler çenelerin herhangi bir bölgesinde oluşabilmekle birlikte; ameloblastom, kalsifiye epitelyal odontojenik tümör ve miksoma benzer olarak, en sık mandibula posterior bölge ve ramusta görülürler.7,9 Radyolojik olarak uniloküler veya multiloküler görünüm sergileyebilen OK'ye çoğunlukla gömülü bir diş eşlik eder. OK'ler klinik olarak ağrı ve şişlik gibi belirtiler gösterebilmekle birlikte asemptomatik de olabilirler. Multiple OK'ler çoğunlukla Nevoid Basal Cell Carsinoma Syndrome (NBCCS) ile birlikte görülür. ${ }^{10} \%$ 25 ila \% 60 arasında yüksek bir nüks oranına sahip olan OK'lerin NBCCS ile ilişkili olduğu vakalarda nüks oranı yaklaşık \% 82 olarak bildirilmiştir. Yüksek nüks potansiyeline sahip kistlerin tedavisinde agresif veya konservatif birçok farklı tedavi yaklaşımı kullanılmıştır. Ancak, ideal tedavi yaklaşımı ile ilgili literatürde hala fikir birliği yoktur. ${ }^{8,11}$

Dentigeröz kist (DK) ikinci en çok görülen odontojenik 
kisttir ve çoğu zaman asemptomatiktir. Daha çok erkek hastalarda 2. ve 3. dekatta gelişim gösterir. ${ }^{6,12} \mathrm{DK}$, artık mine epiteli ile mine arasında veya mine organı tabakaları arasındaki bir sıvı birikimi nedeniyle ortaya çıkar. ${ }^{13}$ Mandibular üçüncü molar ve üst kanin bölgeleri en sık gözlendiği alanlardır. ${ }^{12}$ Klinik olarak DK, uzun bir süre boyunca asemptomatik kalabilir ancak; bazı vakalarda alveolar kemik üzerinde lokalize bir şişlik olarak da kendini gösterebilir. ${ }^{14}$ Tedavi seçenekleri arasında enükleasyon veya marsupyalizasyon yer alır. Genellikle küçük boyuttaki kistlerin tedavisi kist epitelinin bütünüyle enükle edilmesi ve gömülü dişin sürdürülmesi veya çekilmesi ile gerçekleştirilir. Mandibula fraktür riski olan büyük boyutlara ulaşmış kistlerde, sürdürülmesi istenen gömülü dişlerin bulunduğu durumlarda ve sistemik hastalığı olan yaşlı bireylerde ise ilk tedavi seçeneği olarak marsüpyalizasyon düşünülmektedir. ${ }^{15}$

$\mathrm{Bu}$ vaka raporunda mandibulada büyük boyutlara ulaşmış OK ve DK olgularının marsupyalizasyon ile tedavisi sunulmuştur.

\section{OLGU SUNUMU}

\section{OLGU 1}

46 yaşındaki sistemik hastalığı bulunmayan erkek hasta rutin muayene için kliniğimize başvurdu. Hastanın klinik ve radyolojik muayenesinde mandibular sağ kanin dişten sol 3. molar dişe uzanan asemptomatik ve ekspansiyona neden olmamış büyük boyutta radyolüsent lezyon tespit edildi (Resim 1).

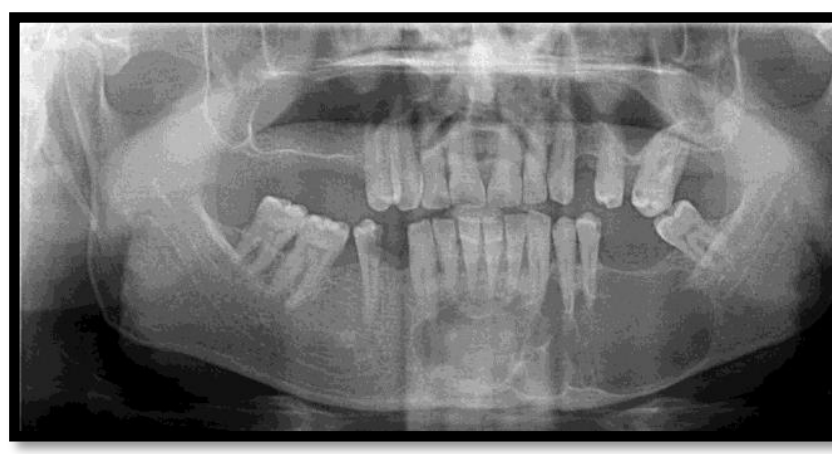

Resim 1.

Odontojenik keratokistin pre-operatif radyografik görüntüsü

Vestibül sulkustan yapılan aspirasyon sonucunda lezyonun odontojenik kist ön tanısıyla marsupyalizasyon yaklaşımı ile tedavisine karar verildi. Hastadan aydınlatımış onam formu alınmasının ardından lokal anestezi altında sol premolar bölgede vestibül sulkustan tam kalınlıkta flep kaldırılarak marsupyalizasyon amacıyla kemikte pencere açıldı. Lezyon içeriğinin boşaltılmasını takiben lezyon epitelinden insizyonel biyopsi için kapsül parçası alındı. Açılan kaviteye gaz iyodoform tampon suture edildi. Hastaya postoperatif antibiyotik (Amoksisilin + Klavulanik Asit, $2 \times 15$ gün boyunca), aneljezik (Parasetamol, 2x1 5 gün boyunca) ve gargara ( $\% 0.12$ 'lik Klorheksidin glukonat, $3 \times 15$ gün boyunca) reçete edildi. Lezyon epitelinden alınan örneklerin histopatolojik incelemesi sonucu, lezyona odontojenik keratokist teşhisi konuldu. Hasta yara bölgesinin bakımı konusunda bilgilendirildi ve 2 haftalık periyotlar ile kontrole çağrılarak kavitenin serum fizyolojik ile irigasyonu sağlandı. 3 ay sonra alınan panoramik radyografide kist boyutlarında belirgin bir küçülme ve periferal yeni kemik oluşumu izlenen lezyonun enükleasyonu gerçekleştirildi. Hasta 1 hafta sonra kontrole çağırıldı. Kontrol seansında yara yerinin sorunsuz iyileştiği görüldü. Hastanın periyodik takibi devam etmektedir (Resim 2).

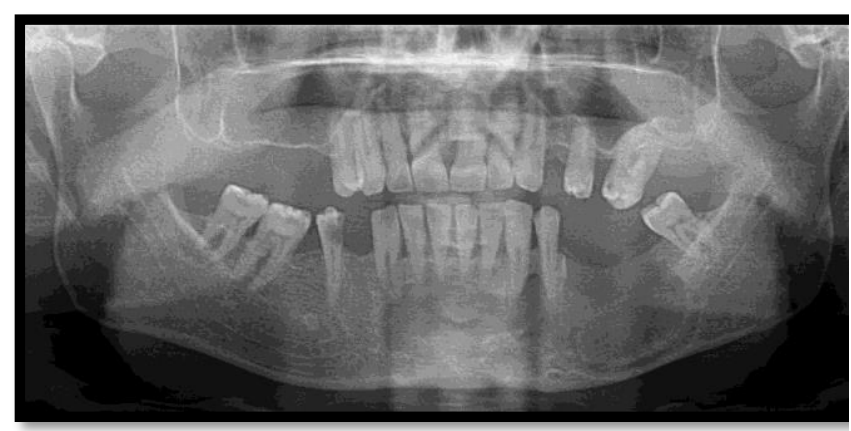

Resim 2

Kontrol seansında kist bölgesinin radyografik görüntüsü

\section{OLGU 2}

21 yaşındaki sistemik hastalığı bulunmayan bayan hasta mandibular sol posterior bölgede ağrı, şişlik ve trismus şikâyeti ile kliniğimize başvurdu. Klinik olarak 2. molar dişin distalinde ramusa uzanan ödem ve kızarıklık tespit edildi. Radyolojik muayene sonrası mandibular 2. molar dişten ramus üst sınırına ulaşan, 3.molar dişi içine alan geniş radyolüsent lezyon tespit edildi (Resim 3).

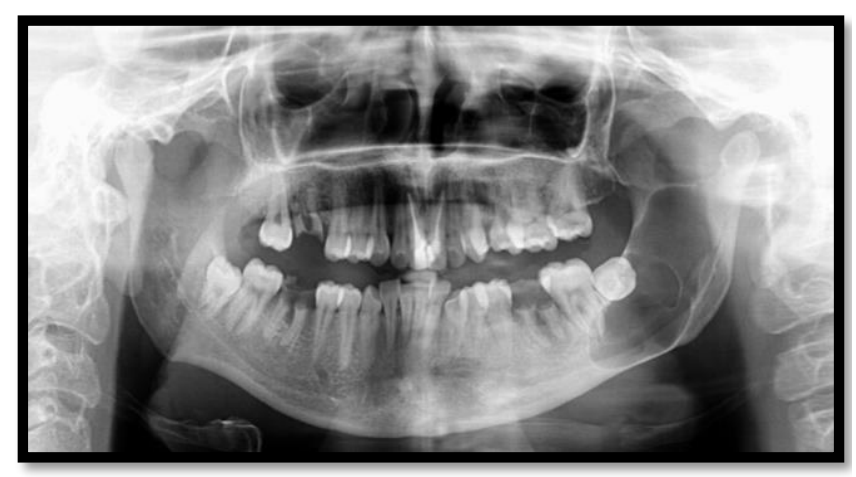

Resim 3.

Dentigeröz kistin pre-operatif radyografik görüntüsü

Radyografide komşu 2. molar dişte herhangi bir rezorbsiyon izlenmedi ve dişin vital olduğu belirlendi. Büyük boyutlara ulaşmış lezyonun çıkarılması sırasında anatomik yapılara zarar verilmemesi için marsupyalizasyon tedavisine karar verildi. Lokal anestezi altında gömülü 3.molar diş çekimi ve kemik penceresi hazırlamak için tam kalınlık flep kaldırılı. Daha sonra diş çekilerek lezyon içeriği aspire edildi. Kavitenin serum fizyolojik ile irigasyonunun ardından 
lezyon epitelinden insizyonel biyopsi alınarak histopatolojik incelemeye gönderildi. Açılan pencereye gaz iyodoform tampon suture edildi ve postoperatif antibiyotik (Amoksisilin + Klavulanik Asit, $2 \times 15$ gün boyunca), aneljezik (Parasetamol, 2x1 5 gün boyunca) ve gargara (\%0.12'lik Klorheksidin glukonat, $3 \times 15$ gün boyunca) reçete edildi (Resim 4).

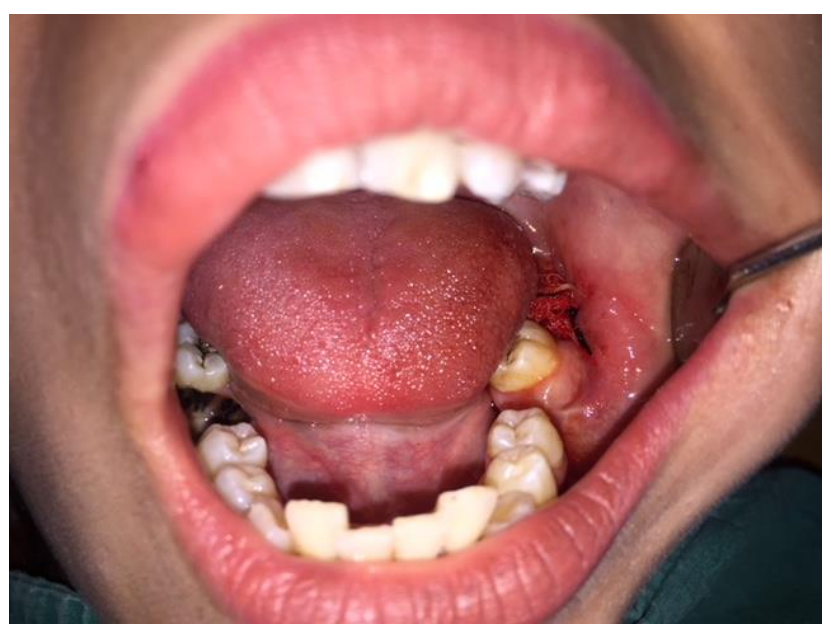

Resim 4.

Kist penceresine gaz iyodoform suture edilmesi

Histopatolojik inceleme sonucu DK tanısı konan hasta 2 haftalık aralıklarla çağırıldı ve kavite serum fizyolojik ile yıkandı. 5 aylık takip sonucu kist boyutlarında belirgin bir küçülme gözlendi ve enükleasyona karar verildi. Lokal anesteziyi takiben 2. molar diş hizasından yükselen ramusa doğru insizyon yapıldı ve tam kalınlık flep kaldırıldı. Kist epiteli tamamen çıkarılarak yara yeri primer suture edildi. Post-operatif medikal tedavi uygulanarak hasta 1 hafta sonra kontrole çağrıldı. Yara bölgesi sorunsuz iyileşen hastanın takibi devam etmektedir (Resim 5).

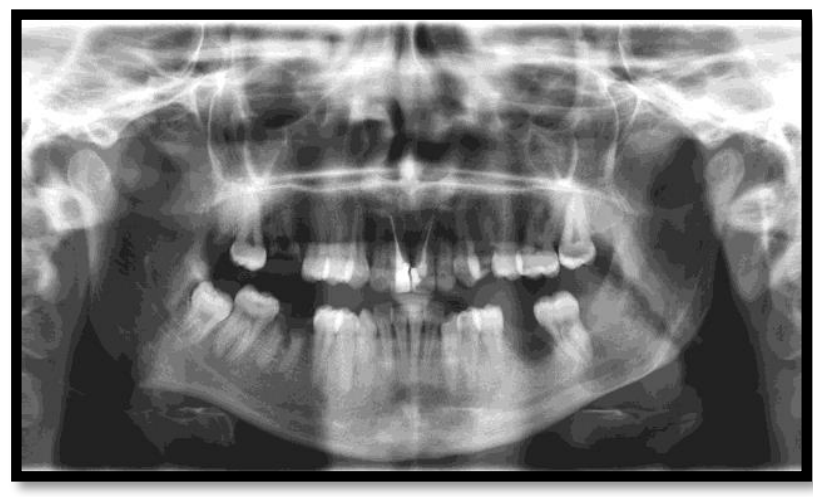

Resim 5

Kontrol seansında kist bölgesinin radyografik görüntüsü

\section{TARTIŞMA}

DK ve OK çenelerde sıklıkla görülen ve çoğu zaman herhangi bir semptom vermeden büyük boyutlara ulaşabilen kistlerdir. OK, yüksek nüks oranına sahip olması nedeniyle farklı tedavi seçenekleri ile tedavi edilebilmektedir. Bu hastalar için evrensel olarak kabul edilen ve en çok kullanılan tedavi yöntemleri; marsupyalizasyonu takiben enükleasyon ile tedavinin gerçekleştirildiği konservatif yöntemler ya da tek başına kimyasal koterizasyon, kriyoterapi veya periferik ostektomi uygulandıktan sonra enükleasyonu içeren agresif yöntemlerdir. Literatürde OK'nin tedavisi için birçok farklı yaklaşım bildirilmiş olmasına rağmen,16 en düşük nüks oranına sahip tedavi yöntemi ile ilgili hala bir netlik yoktur. Al-Moraissi ve ark. $^{7} 2018$ yılında yaptıkları sistematik derlemede OK'lerin enükleasyon ve adjuvan (yardımcı) yaklaşımlar ile tedavisinin marsupyalizsayon ve sekonder kistektomi yaklaşımına göre daha az nüks ile ilişkili olduğunu bildirmişlerdir. Diğer yandan Wushou ve ark.8 çalışmalarında marsupyalizasyonun, OK tedavisinde nüks oranını diğer tedavi seçeneklerine nazaran daha fazla düşürdüğünü ve bu tedavi seçeneğinin OK'nin tedavisinde daha optimal bir yaklaşım olduğunu ileri sürmüşlerdir.

Biz bu vakalarımızda marsupyalizasyon tedavisini tercih ederek kist boyutlarında azalma sağlamayı ve ortaya çıkabilecek mandibula fraktürü, alveolaris inferior siniri hasarı gibi komplikasyonların riskini büyük ölçüde azaltmayı amaçladık. Literatürde, bizim olgularımıza benzer şekilde marsupyalizasyon veya dekompresyonun büyük boyutlara ulaşmış kistlerin tedavisinde daha avantajılı olduğu rapor edilmiştir. ${ }^{17}$

DK' da genel olarak kabul edilen tedavi gömülü dişle birlikte kistin tamamen çıkarılması, yani enükleasyonudur. Ancak gömülü dişin sürebilmesinin mümkün olduğu durumlarda veya geniş çaplı kistlerde eğer enükleasyon çevre vital dokulara zarar verebilme riski taşıyorsa daha konservatif bir yaklaşım olan marsupyalizasyon, tedavi seçeneği olarak göz önünde bulundurulmalıdır. ${ }^{5,7}$ Marsupyalizasyon, tedavinin başından sonuna kadar çok iyi bir hasta uyumu gerektirdiği için bu yaklaşımın endike olduğu vakaların doğru seçilmesi tedavinin başarısını büyük oranda etkilemektedir. ${ }^{18}$ Biz bu vakamızda cerrahi operasyon sırasında çevre dokulara gelebilecek zararı minimuma indirmek için öncelikle marsupyalizyon tedavisini tercih ettik. Bu yaklaşımla kist içi basıncı azaltarak kist kavitesinin boyutlarında belirgin bir küçülme sağladık. Küçük boyutlara ulaşan kisti enükleasyon ile uzaklaştırdık. Bu şekilde vital dokulara verilebilecek potansiyel hasar riskini azaltarak kistin başarılı bir şekilde cerrahi tedavisini gerçekleştirdik. 


\section{SONUÇ}

Çene kistlerinin tedavisinde kullanılacak yaklaşıma karar verilmesi sırasında birçok sistemik ve lokal faktör göz önünde bulundurulmalıdır. Uygun radyografik görüntüleme metotlarıly desteklenen titiz klinik değerlendirme tedavi sırasında ortaya çıkacak olası riskleri minimuma indirecek ve başarılı bir klinik tablo ile sonuçlanacak en konservatif tedavi yönteminin seçiminde yol gösterici olacaktır. İnvaziv tedavilerin (marjinal-segmental rezeksiyon vs.) pre-operatif hospitalizasyon gerektirmesi, rekonstrüksiyon ihtiyacı; post-operatif fonksiyon kaybı, diş ve çevre vital doku hasarı gibi dezavantajları düşünüldüğünde, bu tip vakalarda marsupyalizasyon ile tedavinin daha avantajlı olduğu kanaatindeyiz. Kist ile ilişkili dişlerin ağız içerisine sürdürülmesi, büyük boyutlara ulaşmış kistlerin hacminin azaltılarak enükleasyon yapılması ve yaşlı hastalarda invaziv girişimlerden kaçınmak isteniyorsa marsupyalizasyon primer tedavi olarak düşünülmelidir. 


\section{KAYNAKLAR}

1. Partsch C. Uber kiefercysten. Deutsche Monatsschrift Fur Zahnheilkunde 10, 271, Quoted from Pogrel, MA, 2005. Treatment of keratocysts: The case for decompression and marsupialization. $\mathrm{J}$ Oral Maxillofac Surg. 1892;63:1667-1673.

2. Tolstunov L. Marsupialization catheter. Journal of Oral and Maxillofacial Surgery. 2008;66(5):1077-1079.

3. Pogrel MA. Treatment of keratocysts: The case for decompression and marsupialization. Journal of oral and maxillofacial surgery. 2005;63(11):1667-1673.

4. Sun R, Cai $Y, W u Y$, et al. Marsupialization facilitates movement of the cystic lesion-associated deeply impacted mandibular third molar in spite of its mature roots. Medicina oral, patologia oral y cirugia bucal. 2017;22(5):e625.

5. Gao L, Wang X-L, Li S-M, et al. Decompression as a treatment for odontogenic cystic lesions of the jaw. Journal of Oral and Maxillofacial Surgery. 2014;72(2):327-333.

6. Ghandour L, Bahmad HF, Bou-Assi S. Conservative Treatment of Dentigerous Cyst by Marsupialization in a Young Female Patient: A Case Report and Review of the Literature. Case reports in dentistry. 2018;2018.

7. Al-Moraissi EA, Pogrel MA, Ellis III E. Enucleation with or without adjuvant therapy versus marsupialization with or without secondary enucleation in the treatment of keratocystic odontogenic tumors: A systematic review and meta-analysis. Journal of CranioMaxillofacial Surgery. 2016;44(9):1395-1403.

8. Wushou A, Zhao Y-J, Shao Z-M. Marsupialization is the optimal treatment approach for keratocystic odontogenic tumour. Journal Of Cranio-Maxillofacial Surgery. 2014;42(7):1540-1544.

9. Borghesi A, Nardi C, Giannitto C, et al. Odontogenic keratocyst: imaging features of a benign lesion with an aggressive behaviour. Insights Imaging. 2018.

10. Madras J, Lapointe H. Keratocystic odontogenic tumour: reclassification of the odontogenic keratocyst from cyst to tumour. Tex Dent J. 2008;125(5):446-454.

11.Pogrel MA. Decompression and marsupialization as a treatment for the odontogenic keratocyst. Oral and Maxillofacial Surgery Clinics. 2003;15(3):415-427.

12. Ertas Ü, Yavuz MS. Interesting eruption of 4 teeth associated with a large dentigerous cyst in mandible by only marsupialization. Journal of oral and maxillofacial surgery. 2003;61(6):728-730.

13. Martínez-Pérez D, Varela-Morales M. Conservative treatment of dentigerous cysts in children: a report of 4 cases. Journal of oral and maxillofacial surgery. 2001;59(3):331-333.

14. Fujii R, Kawakami M, Hyomoto $M$, et al. Panoramic findings for predicting eruption of mandibular premolars associated with dentigerous cyst after marsupialization. Journal of Oral and Maxillofacial Surgery. 2008;66(2):272-276.
15. Nishide N, Hitomi G, Miyoshi N. Irrigational therapy of a dentigerous cyst in a geriatric patient: a case report. Special Care in Dentistry. 2003;23(2):70-72.

16. Warburton G, Shihabi A, Ord RA. Keratocystic odontogenic tumor (KCOT/OKC)-Clinical guidelines for resection. Journal of maxillofacial and oral surgery. 2015;14(3):558-564.

17. Mejia JL, Donado JE, Basrani B. Active nonsurgical decompression of large periapical lesions-3 case reports. J Can Dent Assoc. 2004;70(10):691-694.

18. Bouquot JE. Odontogenic cysts and tumors. In: Neville BW, Damm DD, Allen CM,eds Oral and Maxillofacial Pathology 2nd ed Philadelphia: WB Saunders. 2002:683-687.

Yazışma Adresi:

Kadircan KAHVECi

Ordu Üniversitesi,

Diş Hekimliği Fakültesi

Ağız Diş ve Çene Cerrahisi AD,

Ordu, Türkiye

Tel : : +904522121283

E-Posta : kahveci_kadircan@hotmail.com 